\title{
Education management and technology reform in big data era - a new paradigm
}

\author{
Xuejian $\mathrm{Mo}^{1, \mathrm{a}}$ \\ ${ }^{1}$ Tianjin University of Finance and Economics \#25 Zhujiang Rd, Hexi District, TianJin, China 300222 \\ a332970072@qq.com
}

Keywords: Big Data, Education Management Reform, Educational Technology Paradigm, Personalized Adaptive learning

Abstract. With the development of cloud computing and mobile Internet, big data in various fields quickly became a hot topic in education, big data is becoming a disruptive innovation to promote the education system and change the power of science. Starting from the big data features, educational management era of big data is more prominent in the performance of educational management functions in the timeliness of management, prospective, case, integration, weight varying characteristics, bringing great opportunity in education management changes. This article discusses how to effectively manage and utilize big data to better educational management services, and draw a conclusion: due to better implement the "learner-centered" philosophy of education, personalized adaptive learning system will be a new educational technology paradigm based on big data.

\section{Introduction}

Big Data: A Revolution that Will Transform How We Live, Work and Think, written by Viktor Mayer Schonberger and Kenneth Cukier is considered the first of its kind to make big data research, and truly bring big data into the public view. With the rapid development of information technology, education, information technology is experiencing an unprecedented development momentum, the depth of integration of technology and education promotes change and innovation in education. For education managers' part, how to implement the functions of education $t$ involves the education management methods. Education Management in Big Data era is the development of modern science and technology, according to "integrated, mixed, relevant"[1] data to fulfill education management functions, which can be "in a lot of areas and very deep the level of access to and use of comprehensive data, a complete data and system data, in-depth exploration of the laws of the real world, access to knowledge acquired in the past impossible to obtain in the past can not match the (opportunity)[1]. "

This study was designed to investigate the educational management and technological reform issues under conditions of big data, analyzing big data era educational management implementation and realization of educational management functions, for the development of more effective management measures and methods of education, better achieve the Education Management object reference, and gives a new paradigm of big data era educational technology.

\section{Big Data and Scientific Paradigm}

\section{Big Data}

Big data means that the data of the large, typically of the order of PB or DB data. Big data also includes data discovery, collection, connotation and mining applications, its size or complexity beyond the traditional common database and software technology that can manage and process the data set range. Based on the structural state of the set of numbers, large data can be divided into structured data semi-structured and unstructured data[2]. Based on the type of application data, it can also be divided into massive trading data, massive interactive data and massive processing data [3]. Big data feature is also very obvious, to summarize general, namely Volume, Variety, Velocity and Value. 


\section{Big Data of Education Management}

Big data has early warning, forecasting, difference, sharing, dynamic characteristics, is bound to have a profound impact on education management. Big data management involves a wide range of education, behavioral data from the aspect of education management systems, online learning platform and course management platform, manager, trainer, learners in all educational activities as well as everyday human behavior data, can be called educational big data[4].

Scientific Paradigm

In the book: The Structure of Scientific Revolutions written by Thomas Kuhn, it Systematically expounded the concept and theory of paradigm. What we usually call scientific paradigm universally recognized scientific achievements that, for a time, provide model problems and solutions for a community of researchers[5].

\section{Education Management Reform Trend under Background of Big Data}

\section{Early Warning data highlight the timeliness of Education Management}

Early Warning of big data is that with respect to certain criteria, when data is abnormal, through some mechanism to warn, to quickly take appropriate measures so that to solve these problems. This is in line with the principles of management of the bottom line, that is to say, first setting up a tolerance critical point or reference point, and then determining whether the appropriate situation is within the acceptable range or not, otherwise it should take measures to reverse the adverse situation.

Forecasting data highlight the prospective of Education Management

Early warning referring more to a certain critical point to determine adverse events. But forecast mainly to see the trends and possibilities of a thing, that do not necessarily have a reference point, not necessarily an adverse event. According to the education big data management and analysis, it can play a predictive role in student learning and needs, education and educational decision-making of public opinion, so that forward-looking management education.

\section{Difference data highlights the personality of Education Management}

Early warning data and forecasting data is based on more on the macro data. In fact, big data also reflects the micro side, namely by recording and analyzing the behavior of the details related to the user to determine their preferences, in order to strengthen the management of accuracy. Individualized, personalized management and personnel training has been the ideal of education.. Big data is conducive to different individuals based on their data to identify differences in order to strengthen education and management of the target with precision, better education to achieve the above ideal.

Sharing data highlights the integration of Education Management

In education management, "integrated service" emphasizes collaboration service, student-centered services of knowledge management standards, and information technology as an integrated service platform. Openness, equality and freedom and other characteristics of big data makes the massive data resources can be shared by different users, thereby facilitating truly integrated services.

Dynamic data highlight the contingency of Education Management

It seems to contingency management theory that there do not exist universal management principles and methods for a variety of conditions, " All along with the condition set," managers must analyze the relationship between the various factors and trends within and outside the organization between these factors, according to various specific circumstances, to take appropriate management models and approaches. Big data is famous for its mass. Thus, education management based on big data required a contingency management. And fast, convenient and dynamic big data is also conducive to the realization of contingency education management.

\section{Educational Technology Research Paradigm and Its Evolution}

This paper, the educational technology is not defined clearly, it is basically equivalent to educational Technology, instructional technology or instructional development[6], its core is the application of technical research support teaching and learning. Core strategy of educational technology research is 
to design research. From the perspective of research paradigm, the main purpose is to look at the characteristics of educational technology paradigm, and influence the evolution of big data research on educational technology possible.

Educational Technology Paradigm mainly involved four cyber-education technology paradigms, they are CAI (Computer-Assisted Instruction), ITS (Intelligent Tutoring System), Logo-as-Latin and CSCL (Computer-Supported-Collaborative Learning). Their respective characteristics are shown in Table 1.

Table 1 Educational Technology Research Paradigm

\begin{tabular}{c|c|c|c}
\hline $\begin{array}{c}\text { Educational } \\
\text { Technology Paradigm }\end{array}$ & Learning theory & Teaching Model & Research Question \\
\hline CAI & Behaviourism & $\begin{array}{c}\text { Programmed learning/ } \\
\text { instructional design }\end{array}$ & Teaching efficiency \\
\hline ITS & $\begin{array}{c}\text { Information processing } \\
\text { theory }\end{array}$ & $\begin{array}{c}\text { One-to-one training } \\
\text { and interactivity }\end{array}$ & Teaching ability \\
\hline Logo-as-Latin & $\begin{array}{c}\text { Cognitivism and } \\
\text { Constructivism }\end{array}$ & Discovery learning & Transference teaching \\
\hline CSCL & Sociocultural theory & Collaborative learning & Practical teaching \\
\hline
\end{tabular}

\section{Educational Technology Research Paradigm under data-intensive science: PAL}

Data-intensive research methods capture the overall impact of big data bringing by the information age. In different fields, focusing on the different purpose and methods, so having different characteristics. Specific applications of big data in the field of education are mainly divided into LA (Learning Analytic) and EDM (Educational Data Mining). There are not clear bound between EDM and LA, but their origins, theories and goals are different, and becoming two entirely different field of educational technology research.

EDM utilizes statistics, machine learning and data mining methods to analyze the data gathering from teaching and learning process. Siemens then defined LA as " Learning analytics is the use of intelligent data, learner-produced data, and analysis models to discover information and social connections for predicting and advising people's learning " [6].

Based on data-intensive science, LA and EDM technology can better analyze students' needs and characteristics, which makes learning more inclined personalized. Therefore, we believe that based on the data-intensive scientific adaptive learning system should reflect the individual learning characteristics, the next educational technology research paradigm should be PAL (Personalized Adaptive learning), that is based on adaptive learning but also reflects the characteristics and needs of students. According to the characteristics of students (prior knowledge, learning style, etc.) and other information (age, gender, interests, etc.), we can group students (Profiling). Learning system can recommend the learning content to the students according to characteristics of students. Teachers provide a rich learning materials for the different characteristics of students, and students can also choose their own learning materials, assessment methods. PAL system configuration is: learning content generation process: add student background data (past results, course of study, learning styles, etc.) into the prediction model, generate visual data analysis, whereby teachers design learning content for different characteristics of different groups of students.

Unlike previous individualized learning and adaptive learning, PAL based on big data will incorporate data analysis results of EDM and LA, thus be able to provide more suitable learning content for a particular student, get more and more accurate learning activities information and the learner information, better analyze the learning process mode and effectiveness of learning activities, and get a more accurate learning assessment, etc. 


\section{Opportunities and Challenges}

Opportunities and Challenges of Educational Management

On the one hand, support from the national policy of education, information technology, the development of computer science and network technology, wisdom campus and online education platform management practices, relevant software development and deeper scientific research, gave an unprecedented opportunities of big data, which also provides a good opportunity for education management reform. On the other hand, it should be cool to see, along with the rapid arrival of the era of big data, there are many challenges in the hustle and bustle behind the face, there are still many problems to be solved in the quality of personnel, usage, support conditions and other aspects of the data itself.

Opportunities and Challenges of Educational Technology

Big data has brought many possibilities for the development of educational technology, such as creating a personalized adaptive learning environment, knowledge discovery tools, management decision-making platform and so on. While its application faces many challenges, first and foremost challenge is from the data aspects: how to store vast amounts of unstructured data? How to analyze these complex data? How to really understand the data and the results when communicated to the non-data professionals? Second, data-intensive scientific applications reflected mainly in education of LA and EDM, making the learning process transparent by data, and analyzing students' behavior and academic performance based on these data. These data can convey the "what happened", but can not answer "why it happened", especially those do not reflect in the data.

\section{References}

[1] Mayer-Schönberger, Viktor, and Kenneth Cukier. Big data: A revolution that will transform how we live, work, and think. Houghton Mifflin Harcourt, 2013.

[2] GuoZhong Xie. Enterprise management and innovation under the era of big data. Innovation-driven: new opportunities and challenges-2013 National Enterprise Management Innovation Conference compilations. Vol 1(2013), p. 64-69

[3] Information on http://www.informatica.com/downloads/1601_big_data_wp.pdf.

[4] Xu Peng, Wang Yining, Yanhua Liu, Zhang Hai. The Learning Innovation from the Perspective of Big Data: An Analysis of the U.S. Report of Enhancing Teaching and Learning through Educational Data Mining and Learning Analytics and Its Enlightenment. Journey of Distance Education. Vol 6(2003), p. 11-17

[5] Kuhn, Thomas S. "The Structure of Scientific Revolutions. Chicago: U of Chicago P, 1962." The Structure of Scientific Revolutions. 3rd ed. Chicago: U of Chicago P (1970).

[6] Information on http://www.elearnspace.org/blog/2010/08/25/what-are-learning-analytics/ 